\title{
Combined Evaluation of Preoperative Serum CEA and CAI25 as an Independent Prognostic Biomarker in Patients with Early-Stage Cervical Adenocarcinoma
}

OncoTargets and Therapy

\section{Genping Huang $\mathbb{( D}^{1, *}$ \\ Ruizhe Chen $\mathbb{D}^{1, *}$ \\ Nanjia Lu (D) \\ Qin Chen (1D $)^{2}$ \\ Weiguo Lv $\mathbb{D}^{1,3}$ \\ Baohua Li (D) ${ }^{1,3}$}

'Department of Gynecologic Oncology, Women's Hospital, Zhejiang University School of Medicine, Hangzhou, Zhejiang, People's Republic of China; ${ }^{2}$ Department of Pathology, Women's Hospital, Zhejiang University School of Medicine, Hangzhou, Zhejiang, People's Republic of China;

${ }^{3}$ Center of Uterine Cancer Diagnosis \& Therapy of Zhejiang Province, Hangzhou,

Zhejiang, People's Republic of China

*These authors contributed equally to this work
Correspondence: Baohua $\mathrm{Li}$ Department of Gynecologic Oncology, Women's Hospital, Zhejiang University School of Medicine, Hangzhou, Zhejiang 310006, People's Republic of China

Tel $+8657|8706| 50 \mid$

Fax+8657187061878

Email Ibh19787@zju.edu.cn

\begin{abstract}
Purpose: There is currently a lack of research on preoperative prognostic analysis of earlystage cervical adenocarcinoma (ADC). The purpose of our study was to clarify whether preoperative serum tumor-marker levels were of prognostic value in early-stage ADC.

Patients and Methods: We performed a retrospective study of patients with International Federation of Gynecology and Obstetrics (FIGO) stage IA1-IIA1 and pathology-proven invasive ADC. We evaluated the relationship between preoperative serum tumor-marker levels and clinicopathological characteristics, and identified the relative preoperative risk factors affecting disease-free survival (DFS) and overall survival (OS). The optimal cut-off point of meaningful tumor markers was determined by the analysis of receiver operating characteristics (ROC), and the accuracy of the results was evaluated by the area under the curve (AUC).
\end{abstract}

Results: Elevated carcinoembryonic antigen (CEA), carbohydrate antigen 125 (CA125), squamous cell carcinoma antigen (SCC-Ag), alpha-fetoprotein (AFP), carbohydrate antigen 153 (CA153) and carbohydrate antigen 199 (CA199) were associated with certain clinicopathologic features of early-stage ADC. The combination of elevated serum CEA and CA125 was significantly associated with FIGO stage, body mass index (BMI) and LNM. KaplanMeier survival curve and Cox regression analyses revealed that CEA and CA125 might have significant prognostic implications in early-stage ADC patients, and the combination of elevated serum CEA and CA125 served as an independent predictor of early-stage ADC. The optimal cut-off point of serum CA125 for prediction DFS and OS was $32.60 \mathrm{U} / \mathrm{mL}$ and of serum CEA were $2.85 \mathrm{ng} / \mathrm{mL}$ and $2.05 \mathrm{ng} / \mathrm{mL}$, respectively. The AUC showed that serum CEA was a moderate predictor of OS.

Conclusion: The preoperative serum levels of CEA and CA125 might have significant prognostic implications in early-stage ADC patients. Combined preoperative serum CEA and CA125 levels independently predicted the prognosis of early-stage ADC.

Keywords: the early-stage cervical adenocarcinoma, carcinoembryonic antigen, cancer antigen 125 , prognosis

\section{Introduction}

Cervical cancer (CC) is one of the most common gynecological malignancies with cervical squamous cell carcinoma (SCC) accounting for about $80 \sim 85 \%$ of cases while cervical adenocarcinoma (ADC) approaches $15 \sim 20 \%{ }^{1,2}$ The clinical diagnosis of ADC patients is difficult and a reliable noninvasive method for preoperative 
prediction and post-treatment monitoring has not been available. $^{3,4}$ Traditional detection methods are less reliable for ADC due to anterior lesions associated with ADC that are located in deep side depressions of the transformation region of the cervix, making it difficult to obtain effective specimens. ${ }^{5,6}$ Compared to SCC, ADC has usually larger tumor volumes, earlier local invasion and rapid lymph node metastasis. The malignant behavior of ADC is extremely strong, it has the capability of long-distance transmission, is resistant to radiotherapy and systemic chemotherapy and has a particularly poor prognosis. ${ }^{7,8}$ In previous literature, there have been many efforts to enhance the clinicopathological assessment of the predictive prognostic factor of ADC, ${ }^{2,9-11}$ such as International Federation of Gynecology and Obstetrics (FIGO) stage, lymph node metastasis (LNM), stromal invasion, differentiation and tumor size. However, the above studies mainly focused on postoperative predictive prognostic factors, lacking preoperative intervention and assessment. Currently, multiple serum tumor-markers have been described as possible preoperative factors for the screening and monitoring of the clinical course of primary gynecological carcinoma. ${ }^{12-14}$ Earlier studies found that serum carbohydrate antigen 125 (CA125) is an independent prognostic marker for patients with ADC and elevated serum carcinoembryonic antigen (CEA) levels were significantly associated with the presence of lymph node metastasis in ADC. ${ }^{15,16}$ Unfortunately, their roles in early ADC disease have not been defined. In addition, other routinely tested tumor markers, such as squamous cell carcinoma antigen (SCC-Ag), alpha-fetoprotein (AFP), carbohydrate antigen 153 (CA153) and carbohydrate antigen 199 (CA199) have been investigated to correlate with prognosis in human malignancies, ${ }^{10,17-19}$ but there is no evidence that they are associated with the prognosis of early stage ADC. Moreover, recent studies confirmed that the combination of CEA and CA125 could predict prognosis in gastric cancer, pancreatic cancer and breast cancers, but its utility for early-stage ADC has not been identified. ${ }^{20-22}$ Our research aimed to resolve these unanswered questions.

A better method to identify associated preoperative predictive tumor-biomarkers would help to determine the patients who have disease regression and recurrence of early-stage ADC. We aimed to analyze the association of these preoperative serum tumor-markers with clinical parameters indicating poor prognosis and attempted to identify the possible preoperative prognostic predictors of early-stage ADC.

\section{Patients and Methods}

\section{Ethics Statement}

This study was approved by the Institutional Review Board of Women's Hospital, Zhejiang University School of Medicine. All patients provided written informed consent and the study was conducted in accordance with the Declaration of Helsinki.

\section{Patients}

This retrospective study enrolled 212 patients with earlystage ADC treated at Women's Hospital, Zhejiang University School of Medicine between January 2005 and December 2015. Patients who lacked serum tumor-marker data ( 7 cases) were excluded. The remaining 205 patients who received standard treatment and did not receive any anticancer therapy prior to their surgery were enrolled in the study. There were 188 patients with accurate follow-up data for at least 3 years between January 2010 and December 2018. Demographic and clinicopathologic characteristics were collected from medical records and included: age, FIGO stage, body mass index (BMI), menopause status, tumor size, myometrial invasion, vaginal wall extension, parametrial extension, endometrial extension, lymph vascular space invasion (LVSI), LNM, surgical margin, histological type and preoperative tumor-markers.

\section{Preoperative Serum Tumor-Markers Examination}

All patients were diagnosed with early-stage ADC by pathologists in our hospital and initial values of preoperative serum tumor-markers were drawn and tested prior to initiation of treatment. In total, $3 \mathrm{~mL}$ venous blood samples were collected from each subject in the morning on an empty stomach. The samples were centrifuged at $3000 \mathrm{rpm}$ (SORVALL ${ }^{\circledR}$, floor-type refrigerated centrifuge) for $10 \mathrm{~min}$ at $22-24^{\circ} \mathrm{C}$ before being sent for tumor-marker analysis. The assay was performed directly on non-citrated serum. If tumor-marker analysis was carried out within $24 \mathrm{~h}$ of collection, samples were refrigerated at $0-4^{\circ} \mathrm{C}$. Otherwise, the samples were divided into aliquots and deep frozen $\left(-70^{\circ} \mathrm{C}\right)$ until required. The serum tumor markers were estimated using an automated chemiluminescence analyzer (Shanghai Roche Diagnostic products Co., LTD., CHINA). All assay procedures were performed according to manufacturer instructions. The criterion of normal upper limits of these serum tumor-markers are based on $<$ Common used serum tumor marker tests: clinical practice and quality management>, issued by the national health commission, PRC. The normal upper limits 
were as follows: SCC-Ag was $1.5 \mathrm{ng} / \mathrm{mL}$, CEA was 5.0 $\mathrm{ng} / \mathrm{mL}$, AFP was $7.0 \mathrm{ng} / \mathrm{mL}$, CA125 was $35 \mathrm{U} / \mathrm{mL}$, CA153 was $25 \mathrm{U} / \mathrm{mL}$ and CA199 was $39 \mathrm{U} / \mathrm{mL}$. In addition, 50 enrolled cases lacked preoperative serum SCC-Ag data, 125 enrolled cases lacked preoperative serum CA199 data.

\section{Operative Process}

All enrolled ADC patients underwent surgery by the oncology team at Women's Hospital, Zhejiang University School of Medicine according to NCCN (National Comprehensive Cancer Network) guidelines. All patients were no fertility sparing. Patients of stage IA1 without LVSI underwent extrafascial hysterectomy; stage IA1 with LVSI and stage IA2 underwent modified radical hysterectomy with pelvic lymph node dissection with or without bilateral adnexectomy with or without para-aortic lymph node dissection; stage IB1, stage IB2 and stage IIA1 underwent radical hysterectomy with pelvic lymph node dissection with or without bilateral adnexectomy with or without para-aortic lymph node dissection. All specimens were fixed in formalin for $24-48 \mathrm{~h}$ and examined by both surgeons and pathologists. The pathologists then prepared, stained and read the specimen slices. The surgical specimens were histologically evaluated according to the World Health Organization classification criteria. The senior pathologist reviewed all histologic parameters, including differentiation, tumor size, myometrial invasion, vaginal wall extension, parametrial extension, endometrial extension, LVSI, LNM, surgical margin and histological type. Clinical stage and histological type were based on criteria established by the FIGO guidelines. Tumor size was evaluated by the attending gynecologic oncologist during the preoperative pelvic examination and the tumors were classified into 2 groups: $\geq 4 \mathrm{~cm}$ or $<4 \mathrm{~cm}$. Myometrial invasion was grouped into deep and superficial invasion, based on the ratio of tumor invading the cervical stroma to more than $2 / 3$ of the cervical thickness. The histology samples were grouped into pure adenocarcinoma and others types (including clear cell adenocarcinoma, serous adenocarcinoma and middle tubular adenocarcinoma).

\section{Follow-Up}

Patients with early-stage ADC were followed-up postoperatively by interview at the clinic or by phone call. Patients were followed-up clinically every 3 months for the first year, every 4 months for the second year and then every 6 months until they remained without evidence of disease for 3 years. Regional tumor recurrence, distant metastasis and patient survival were recorded. Follow-up ended in December 2018. Among them, 17 patients $(17 / 205,8.29 \%)$ were lost to followup.

\section{Results \\ Patient Characteristics}

A total of 205 patients with the early-stage ADC were enrolled into the study. The mean patient age was 38.4 (range 28-71) years. Overall, 16 patients (7.8\%) were stage IA1; 4 patients $(2.0 \%)$ were stage IA2; 150 patients $(73.2 \%)$ were stage IB1; 14 patients $(6.8 \%)$ were stage IB2; 21 patients $(10.2 \%)$ were stage IIA1. Of these, 28 patients (13.7\%) were postmenopausal; 23 patients (11.2\%) were poorly differentiated; 30 patients $(14.6 \%)$ had tumors $\geq 4 \mathrm{~cm} ; 49$ patients $(23.9 \%)$ were obese; 56 patients $(27.3 \%)$ had deep of myometrial invasion; 12 patients $(5.9 \%)$ involved the vaginal wall; 4 patients $(2.0 \%)$ had parametrial extension; 11 patients $(5.4 \%)$ had endometrial extension; 15 patients (7.3\%) had LVSI; 21 (10.2\%) had LNM; 2 patients $(1.0 \%)$ had surgical margin positive; 36 patients $(17.6 \%)$ were pure adenocarcinoma. Preoperative serum SCC-Ag was elevated (range 0.17-4.18 $\mathrm{ng} / \mathrm{mL}$ ) in $7.1 \%$ (11 of 155), CEA (range $0.3-219.9 \mathrm{ng} / \mathrm{mL}$ ) in $10.7 \%$ (22 of 205), AFP (range $0.6-9.4 \mathrm{ng} / \mathrm{mL}$ ) in $0.5 \%$ (1 of 205), CA125 (range 2.6-317.4 U/mL) in 10.7\% (22 of 205), CA153 (range 1.3-32.6 U/mL) in 1.0\% (2 of 205) and CA199 (range $0.6-938.3 \mathrm{U} / \mathrm{mL}$ ) in $6.2 \%$ (5 of 80 ). As shown in Table 1, elevated CA125 was significantly associated with degree of myometrial invasion $(\mathrm{P}=0.011)$ and LNM $(\mathrm{P}=0.002)$. Elevated CEA was significantly associated with BMI $(\mathrm{P}=0.012)$ and degree of myometrial invasion $(\mathrm{P}=0.002)$. The combination of serum CA125 and CEA was significantly associated with FIGO stage $(\mathrm{P}=0.004)$, BMI $(\mathrm{P}=0.029)$ and LNM $(\mathrm{P}=0.037)$. As shown in Supplementary Table S1, elevated SCC-Ag was significantly associated with histological type $(\mathrm{P}=0.004)$, elevated AFP was significantly associated with parametrial extension $(\mathrm{P}=0.020)$, elevated CA199 was significantly associated with myometrial invasion $(\mathrm{P}=0.019)$, vaginal wall extension $(\mathrm{P}=0.001)$ and endometrial extension $(\mathrm{P}=0.009)$, there is no significance in elevated serum CA153.

\section{Survival Analysis}

During follow-up, 20 patients out of 188 (10.64\%) experienced clinical recurrence and 17 (9.04\%) died of progressive disease. Their median follow-up time was 51 months (range 3-165 months). Survival curves show the correlation 
Table I The Correlation Between Expression of Tumor Markers (CAI25, CEA and Combination of CAI25 and CEA) and Clinicopathological Characteristics in Patients with Early-Stage Cervical Adenocarcinoma Characteristics

\begin{tabular}{|c|c|c|c|c|c|c|c|c|c|}
\hline & \multicolumn{2}{|c|}{ CAI $25, n(\%)$} & \multirow[t]{2}{*}{$P$} & \multicolumn{2}{|l|}{ CEA, $n(\%)$} & \multirow[t]{2}{*}{$\mathbf{P}$} & \multicolumn{2}{|c|}{ Combination of $\mathrm{Cal} 25$ and CEA, $n(\%)$} & \multirow[t]{2}{*}{$\mathbf{P}$} \\
\hline & Abnormal & Normal & & Abnormal & Normal & & Both Abnormal & Others & \\
\hline $\begin{array}{l}\text { Patient age (years) } \\
\leq 50 \\
>50\end{array}$ & $\begin{array}{l}18(8.8) \\
4(2.0)\end{array}$ & $\begin{array}{l}126(6 \mid .5) \\
57(27.8)\end{array}$ & 0.209 & $\begin{array}{l}16(7.8) \\
6(2.9)\end{array}$ & $\begin{array}{l}128(62.4) \\
55(26.8)\end{array}$ & 0.787 & $\begin{array}{l}6(2.9) \\
2(1.0)\end{array}$ & $\begin{array}{l}138(67.3) \\
59(28.8)\end{array}$ & 1.000 \\
\hline $\begin{array}{l}\text { FIGO stage } \\
\text { I } \\
\text { II }\end{array}$ & $\begin{array}{l}17(8.3) \\
5(2.4)\end{array}$ & $\begin{array}{l}167(81.5) \\
16(7.8)\end{array}$ & 0.095 & $\begin{array}{l}17(8.3) \\
5(2.4)\end{array}$ & $\begin{array}{l}167(81.5) \\
16(7.8)\end{array}$ & 0.095 & $\begin{array}{l}4(2.0) \\
4(2.0)\end{array}$ & $\begin{array}{l}180(87.8) \\
17(8.3)\end{array}$ & $0.004^{*}$ \\
\hline $\begin{array}{l}\text { BMI } \\
\leq 24.9 \\
>24.9\end{array}$ & $\begin{array}{l}14(6.8) \\
8(3.9)\end{array}$ & $\begin{array}{l}\mid 42(69.3) \\
4 \mid(20.0)\end{array}$ & 0.147 & $\begin{array}{l}12(5.9) \\
10(4.9)\end{array}$ & $\begin{array}{l}144(70.2) \\
39(19.0)\end{array}$ & $0.012^{*}$ & $\begin{array}{l}3(1.5) \\
5(2.4)\end{array}$ & $\begin{array}{l}\text { I53 (74.6) } \\
44(21.5)\end{array}$ & $0.029 *$ \\
\hline $\begin{array}{l}\text { Menopause } \\
\text { Yes } \\
\text { No }\end{array}$ & $\begin{array}{l}5(2.4) \\
17(8.3)\end{array}$ & $\begin{array}{l}23(11.2) \\
160(78.0)\end{array}$ & 0.326 & $\begin{array}{l}4(2.0) \\
18(8.8)\end{array}$ & $\begin{array}{l}24(11.7) \\
159(77.6)\end{array}$ & 0.745 & $\begin{array}{l}2(1.0) \\
6(2.9)\end{array}$ & $\begin{array}{l}26(12.7) \\
|7|(83.4)\end{array}$ & 0.669 \\
\hline $\begin{array}{l}\text { Differentiation } \\
\text { Well/moderate } \\
\text { Poor }\end{array}$ & $\begin{array}{l}17(8.3) \\
5(2.4)\end{array}$ & $\begin{array}{l}165(80.5) \\
18(8.8)\end{array}$ & 0.146 & $\begin{array}{l}17(8.3) \\
5(2.4)\end{array}$ & $\begin{array}{l}165(80.5) \\
18(8.8)\end{array}$ & 0.146 & $\begin{array}{l}6(2.9) \\
2(1.0)\end{array}$ & $\begin{array}{l}176(85.9) \\
21(10.2)\end{array}$ & 0.222 \\
\hline $\begin{array}{l}\text { Tumor size }(\mathrm{cm}) \\
<4 \\
\geq 4\end{array}$ & $\begin{array}{l}17(8.3) \\
5(2.4)\end{array}$ & $\begin{array}{l}158(77.1) \\
25(12.2)\end{array}$ & 0.414 & $\begin{array}{l}2 \mathrm{I}(10.2) \\
\mathrm{I}(0.5)\end{array}$ & $\begin{array}{l}154(75.1) \\
29(14.1)\end{array}$ & 0.272 & $\begin{array}{l}7(3.4) \\
I(0.5)\end{array}$ & $\begin{array}{l}168(82.0) \\
29(14.1)\end{array}$ & 1.000 \\
\hline $\begin{array}{l}\text { Myometrial invasion } \\
<2 / 3 \\
\geq 2 / 3\end{array}$ & $\begin{array}{l}\text { II (5.4) } \\
\text { II (5.4) }\end{array}$ & $\begin{array}{l}138(67.3) \\
45(22.0)\end{array}$ & $0.011^{*}$ & $\begin{array}{l}10(4.9) \\
12(5.9)\end{array}$ & $\begin{array}{l}139(67.8) \\
44(21.5)\end{array}$ & $0.002 *$ & $\begin{array}{l}4(2.0) \\
4(2.0)\end{array}$ & $\begin{array}{l}145(70.7) \\
52(25.4)\end{array}$ & 0.287 \\
\hline $\begin{array}{l}\text { Vaginal wall extension } \\
\text { No } \\
\text { Yes }\end{array}$ & $\begin{array}{l}20(9.8) \\
2(1.0)\end{array}$ & $\begin{array}{l}173(84.4) \\
10(4.9)\end{array}$ & 0.838 & $\begin{array}{l}20(9.8) \\
2(1.0)\end{array}$ & $\begin{array}{l}173(84.4) \\
10(4.9)\end{array}$ & 0.838 & $\begin{array}{l}7(3.4) \\
I(0.5)\end{array}$ & $\begin{array}{l}\text { I } 86(90.7) \\
\text { II (5.4) }\end{array}$ & 0.388 \\
\hline $\begin{array}{l}\text { Parametrial extension } \\
\text { No } \\
\text { Yes }\end{array}$ & $\begin{array}{l}20(9.8) \\
2(1.0)\end{array}$ & $\begin{array}{l}|8|(88.3) \\
2(1.0)\end{array}$ & 0.058 & $\begin{array}{l}20(9.8) \\
2(1.0)\end{array}$ & $\begin{array}{l}|8|(88.3) \\
2(1.0)\end{array}$ & 0.058 & $\begin{array}{l}7(3.4) \\
I(0.5)\end{array}$ & $\begin{array}{l}194(94.6) \\
3(1.5)\end{array}$ & 0.148 \\
\hline $\begin{array}{l}\text { Endometrial extension } \\
\text { No } \\
\text { Yes }\end{array}$ & $\begin{array}{l}19(9.3) \\
3(1.5)\end{array}$ & $\begin{array}{l}175(85.4) \\
8(3.9)\end{array}$ & 0.186 & $\begin{array}{l}20(9.8) \\
2(1.0)\end{array}$ & $\begin{array}{l}174(84.9) \\
9(4.4)\end{array}$ & 0.749 & $\begin{array}{l}7(3.4) \\
I(0.5)\end{array}$ & $\begin{array}{l}187(91.2) \\
10(4.9)\end{array}$ & 0.362 \\
\hline $\begin{array}{l}\text { LVSI } \\
\text { No } \\
\text { Yes }\end{array}$ & $\begin{array}{l}19(9.3) \\
3(1.5)\end{array}$ & $\begin{array}{l}17 \mid(83.4) \\
12(5.9)\end{array}$ & 0.440 & $\begin{array}{l}2 I(10.2) \\
I(0.5)\end{array}$ & $\begin{array}{l}169(82.4) \\
14(6.8)\end{array}$ & 0.924 & $\begin{array}{l}7(3.4) \\
I(0.5)\end{array}$ & $\begin{array}{l}183(89.3) \\
14(6.8)\end{array}$ & 0.461 \\
\hline $\begin{array}{l}\text { LNM } \\
\text { No } \\
\text { Yes }\end{array}$ & $\begin{array}{l}15(7.3) \\
7(3.4)\end{array}$ & $\begin{array}{l}169(82.4) \\
14(6.8)\end{array}$ & $0.002 *$ & $\begin{array}{l}18(8.8) \\
4(2.0)\end{array}$ & $\begin{array}{l}166(81.0) \\
17(8.3)\end{array}$ & 0.354 & $\begin{array}{l}5(2.4) \\
3(1.5)\end{array}$ & $\begin{array}{l}179(87.3) \\
18(8.8)\end{array}$ & $0.037^{*}$ \\
\hline $\begin{array}{l}\text { Surgical margin } \\
\text { Clear } \\
\text { Involved }\end{array}$ & $\begin{array}{l}22(10.7) \\
0(0.0)\end{array}$ & $\begin{array}{l}|8|(88.3) \\
2(1.0)\end{array}$ & 1.000 & $\begin{array}{l}22(10.7) \\
0(0.0)\end{array}$ & $\begin{array}{l}|8|(88.3) \\
2(1.0)\end{array}$ & 1.000 & $\begin{array}{l}8(3.9) \\
0(0.0)\end{array}$ & $\begin{array}{l}195(95.1) \\
2(1.0)\end{array}$ & 1.000 \\
\hline $\begin{array}{l}\text { Histological type } \\
\text { Pure adenocarcinoma } \\
\text { Other }\end{array}$ & $\begin{array}{l}2(1.0) \\
20(9.8)\end{array}$ & $\begin{array}{l}34(16.6) \\
149(72.7)\end{array}$ & 0.419 & $\begin{array}{l}4(2.0) \\
18(8.8)\end{array}$ & $\begin{array}{l}32(15.6) \\
151(73.7)\end{array}$ & 1.000 & $\begin{array}{l}\text { I (0.5) } \\
7(3.4)\end{array}$ & $\begin{array}{l}35(17.1) \\
162(79.0)\end{array}$ & 1.000 \\
\hline
\end{tabular}

Note: *Significant differences $(\mathrm{P}<0.05)$ of the associations between prognostic value and disease-free and overall survival rates in patients with early-stage cervical adenocarcinoma.

Abbreviations: FIGO, International Federation of Gynecology and Obstetrics; BMI, body mass index; LVSI, lymph vascular space invasion; LNM, lymph node metastasis. 
of preoperative serum tumor marker levels with DFS and OS (Figure 1 and Supplementary Figure S1). Kaplan-Meier analysis indicated that elevated serum CA125 was associated with shorter DFS $(\mathrm{P}=0.009, \mathrm{n}=22)$ while elevated serum CEA was significantly associated with shorter DFS $(\mathrm{P}=0.022, \mathrm{n}=22)$ and $\mathrm{OS}(\mathrm{P}=0.024, \mathrm{n}=22)$. Moreover, when the combination of serum CEA and CA125 was examined for prognostic value, the correlation with shorter DFS $(\mathrm{P}=0.001, \mathrm{n}=8)$ and $\mathrm{OS}(\mathrm{P}=0.002, \mathrm{n}=8)$ was more significant. However, other preoperative serum tumor markers (SCC-Ag, AFP, CA153 and CA199) showed no correlation with DFS and OS in these patients. Tables 2 and 3 present the results of univariate and multivariate Cox regression models, respectively. Cox univariate proportional hazards analysis showed that FIGO stage, differentiation, myometrial invasion, parametrial extension, endometrial extension and preoperative serum tumor markers (CA125, CEA and their combination) were significantly correlated with shorter DFS $(\mathrm{P}<0.05)$, as well as FIGO stage, differentiation, myometrial invasion, parametrial extension, endometrial extension and preoperative serum tumor markers (CEA, combination of serum CA125 and CEA) were significantly correlated with $\mathrm{OS}(\mathrm{P}<0.05)$. Multivariate analyses showed that the combination of serum CA125 and CEA, FIGO stage, differentiation and myometrial invasion were independent prognostic factors of DFS and serum CA125 and CEA, FIGO stage, differentiation and myometrial invasion were independent prognostic factors of OS in early-stage ADC patients $(\mathrm{P}<0.05)$.

\section{Receiver Operating Characteristic Analysis}

ROC curves for preoperative serum levels of CA125 and CEA to predict DFS and OS are presented in Figure 2A and $\mathrm{B}$. The AUCs for CA125 and CEA in predicting DFS were 0.565 (95\% CI: $0.410-0.719, \mathrm{P}=0.343)$ and 0.676 (95\% CI: $0.533-0.820, \quad \mathrm{P}=0.010$ ), respectively. The AUCs for CA125 and CEA in predicting OS were 0.561 (95\% CI: $0.388-0.733, \mathrm{P}=0.409)$ and 0.712 (95\% CI: $0.554-0.870, \mathrm{P}=0.004)$. Table 4 shows the optimal cutoff values and corresponding sensitivity and specificity of each index for predicting DFS and OS. CA125 had the greatest Youden index values for predicting DFS (0.25) and OS (0.25). The optimal CA125 cut-offs for predicting DFS and OS were both $32.60 \mathrm{U} / \mathrm{mL}$. CEA had the greatest Youden index values for predicting DFS (0.35) and OS (0.45). The optimal CEA cut-offs for predicting DFS and OS were $2.85 \mathrm{ng} / \mathrm{mL}$ and $2.05 \mathrm{ng} / \mathrm{mL}$.

\section{Discussion}

In recent years, $\mathrm{ADC}$ has shown an upward trend and the incidence of early stage ADC accounts for about $60-70 \%$ of all patients. Compared with SCC, ADC has a relatively strong invasive biological behavior and a worse prognosis. ${ }^{8,23,24}$ The overall survival rates for the early stage SCC and ADC were $90 \%$ and $60 \%$, respectively. ${ }^{2}$ To improve patient's outcome, the current study aimed to look for prognosis predictors of early stage ADC and concluded that preoperative serum CEA and CA125 might have significant prognostic value in early-stage ADC. Furthermore, combined preoperative serum CEA and CA125 levels independently predicted OS and DFS of early-stage ADC, which defines a group of patients at high risk for recurrence and mortality.

In previous studies, ${ }^{25-28}$ intrinsic tumor characteristics such as FIGO stage, grade, histological type and LNM have been shown to be significant prognostic value for survival in ADC patients. Similarly, our multivariate analysis showed tumor differentiation and degree of myometrial invasion are also independent predictors of early stage ADC. However, they are postoperative pathologic prediction risk factors, as studies on preoperative predictors of early-stage ADC are scarce. Hence, the ability to distinguish patients with adverse preoperative prognosis predictors of early stage $\mathrm{ADC}$ is crucial so that they may receive staging surgery and be given adjuvant therapy. Preoperative tumor markers can be detected in serum regardless of the progression of malignant tumors. ${ }^{29}$ The detection of tumor markers with malignant disease offers a novel solution for preoperative prediction of early malignant tumors. ${ }^{30}$ Some tumorassociated antigens have been measured in serum from patients with malignancy and were found to be related to the clinical course of disease. ${ }^{31}$ Other malignancies closely related to gynecologic cancers have examined serum markers, ${ }^{32-35}$ including SCC-Ag, AFP, CA153, CEA, CA125 and CA199 have been of great value for evaluation of pretreatment, treatment effect and for follow-up and establishment of patient prognoses. In our study, we collected clinicopathological data of the early stage ADC patients and analyzed the association of pre-operative serum tumor markers with prognostic value, in order to look for predictive risk factors. Data from our study may help provide more useful tools for prognostic purposes and disease assessment in the postoperative and surveillance period. 

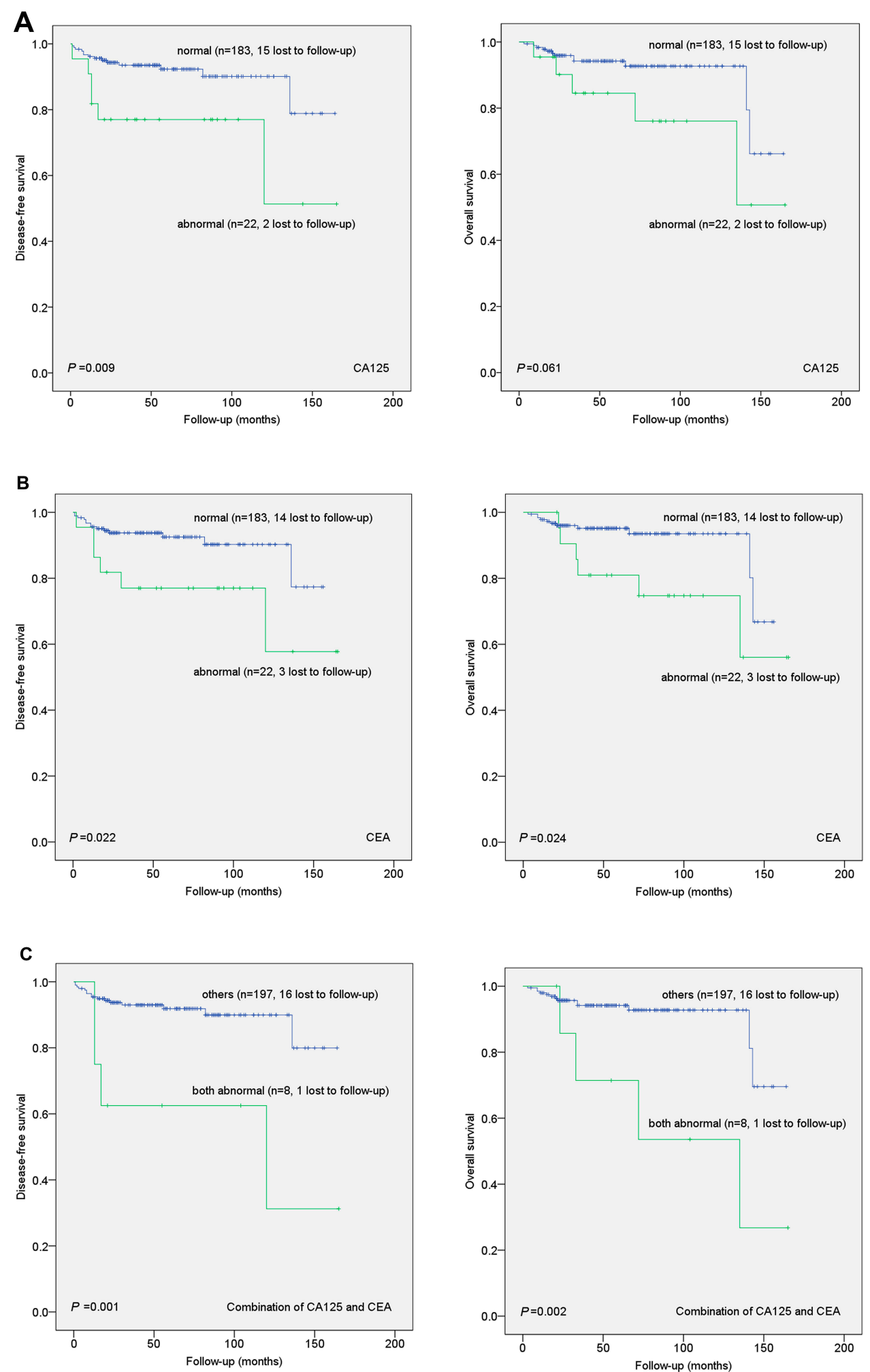

Figure I Kaplan-Meier curves showing the association of aberrant expression of CAI25, CEA and combination of CAI25 and CEA with patient disease-free survival (DFS) and overall survival (OS). Abnormal CAI25 (A), CEA (B), as well as combination of CAI25 and CEA (C), were significantly associated with shorter DFS and OS.

According to this study, preoperative serum CEA and CA125 were useful tumor markers in early stage ADC. Among previous studies, serum CEA and CA125 were useful markers for detection and monitoring of the clinical course of CC and closely correlated with the clinicopathological features of ADC, more than with SCC. ${ }^{15,16}$ Similar 
Table 2 Univariate Analysis of the Associations Between Prognostic Value and Disease-Free and Overall Survival Rates in Patients with Early-Stage Cervical Adenocarcinoma

\begin{tabular}{|c|c|c|c|c|c|c|}
\hline \multirow[t]{2}{*}{ Variable } & \multicolumn{3}{|c|}{ Disease-Free Survival } & \multicolumn{3}{|c|}{ Overall Survival } \\
\hline & HR & $95 \% \mathrm{Cl}$ & $P$ & HR & $95 \% \mathrm{Cl}$ & $P$ \\
\hline Patient age (years) & 2.042 & $0.846-4.927$ & 0.112 & 1.694 & $0.643-4.459$ & 0.286 \\
\hline FIGO stage & 6.300 & $2.551-15.558$ & $6.60 \mathrm{E}^{-5^{*}}$ & 4.223 & $1.47 \mid-12.121$ & $0.007^{*}$ \\
\hline BMI & 1.944 & $0.789-4.788$ & 0.148 & 2.001 & $0.757-5.288$ & 0.162 \\
\hline Menopause & 1.564 & $0.52 I-4.695$ & 0.425 & 1.142 & $0.327-3.992$ & 0.836 \\
\hline Differentiation & 5.980 & $2.442-14.643$ & $9.10 \mathrm{E}^{-5^{*}}$ & 5.181 & $1.945-13.803$ & $0.00 I^{*}$ \\
\hline Tumor size $(\mathrm{cm})$ & 1.053 & $0.308-3.597$ & 0.935 & 0.848 & $0.194-3.713$ & 0.827 \\
\hline Myometrial invasion & 7.627 & $2.908-20.008$ & $3.60 \mathrm{E}^{-5^{*}}$ & 5.916 & $2.182-16.04 \mid$ & $4.78 \mathrm{E}^{-4^{*}}$ \\
\hline Vaginal wall extension & 3.397 & $0.989-11.666$ & 0.052 & 3.284 & $0.733-14.713$ & 0.120 \\
\hline Parametrial extension & 9.634 & $2.204-42.112$ & $0.003^{*}$ & 11.434 & $2.546-51.343$ & $0.00 I^{*}$ \\
\hline Endometrial extension & 6.278 & $2.268-17.380$ & $4.06 \mathrm{E}^{-4^{*}}$ & 3.931 & $1.210-12.767$ & $0.023^{*}$ \\
\hline LVSI & 0.747 & $0.100-5.598$ & 0.776 & 1.097 & $0.143-8.395$ & 0.929 \\
\hline LNM & 1.504 & $0.438-5.169$ & 0.517 & 1.958 & $0.560-6.847$ & 0.293 \\
\hline Surgical margin & 0.049 & $0.000-6.309 E^{+8}$ & 0.800 & 0.049 & $0.000-1.934 \mathrm{E}^{+14}$ & 0.869 \\
\hline Histological type & 0.524 & $0.121-2.257$ & 0.385 & 0.624 & $0.142-2.735$ & 0.532 \\
\hline SCC & 1.102 & $0.142-8.540$ & 0.926 & 1.372 & $0.171-11.004$ & 0.766 \\
\hline CAI 25 & 3.358 & $1.28 \mathrm{I}-8.803$ & $0.014^{*}$ & 2.649 & $0.918-7.644$ & 0.071 \\
\hline AFP & 0.049 & $0.000-5.437 \mathrm{E}^{+11}$ & 0.844 & 0.049 & $0.000-9.850 \mathrm{E}^{+12}$ & 0.858 \\
\hline CEA & 2.972 & $1.124-7.860$ & $0.028^{*}$ & 3.050 & $1.105-8.416$ & $0.031^{*}$ \\
\hline CAI53 & 0.049 & $0.000-6.855 \mathrm{E}^{+8}$ & 0.800 & 0.049 & $0.000-2.287 \mathrm{E}^{+11}$ & 0.840 \\
\hline CA199 & 4.504 & $0.502-40.366$ & 0.179 & 8.572 & $0.775-94.778$ & 0.080 \\
\hline Combination of CAI 25 and CEA & 5.492 & $1.803-16.729$ & $0.003^{*}$ & 5.141 & $1.623-16.287$ & $0.005^{*}$ \\
\hline
\end{tabular}

Note: *Significant differences $(\mathrm{P}<0.05)$ of the associations between prognostic value and disease-free and overall survival rates in patients with early-stage cervical adenocarcinoma.

Abbreviations: FIGO, International Federation of Gynecology and Obstetrics; BMI, body mass index; LVSI, lymph vascular space invasion; LNM, lymph node metastasis; $\mathrm{HR}$, hazard ratio; $95 \% \mathrm{Cl}, 95 \%$ confidence interval.

Table 3 Multivariate Analysis of the Associations Between Prognostic Value and Disease-Free and Overall Survival Rates in Patients with Early-Stage Cervical Adenocarcinoma

\begin{tabular}{|c|c|c|c|c|c|c|}
\hline \multirow[t]{2}{*}{ Variable } & \multicolumn{3}{|c|}{ Disease-Free Survival } & \multicolumn{3}{|c|}{ Overall Survival } \\
\hline & HR & $95 \% \mathrm{Cl}$ & $P$ & HR & $95 \% \mathrm{Cl}$ & $P$ \\
\hline FIGO stage & 2.714 & $1.051-7.011$ & $0.039 *$ & 1.357 & $0.343-5.369$ & 0.664 \\
\hline Differentiation & 3.841 & $1.498-9.849$ & $0.005^{*}$ & 3.279 & $1.200-8.957$ & $0.021 *$ \\
\hline Myometrial invasion & 4.846 & $1.680-13.983$ & $0.004^{*}$ & 4.853 & $1.718-13.712$ & $0.003 *$ \\
\hline Parametrial extension & 1.208 & $0.181-8.056$ & 0.845 & 3.41 & $0.423-27.488$ & 0.249 \\
\hline Endometrial extension & $1.54 \mid$ & $0.427-5.568$ & 0.509 & 0.705 & $0.139-3.582$ & 0.674 \\
\hline CAI 25 & 1.412 & $0.300-6.646$ & 0.662 & - & - & - \\
\hline CEA & 0.915 & $0.189-4.428$ & 0.912 & 0.841 & $0.167-4.223$ & 0.833 \\
\hline Combination of CAI 25 and CEA & 3.325 & $1.048-10.550$ & $0.04 I^{*}$ & 5.152 & $1.653-16.055$ & $0.005 *$ \\
\hline
\end{tabular}

Note: *Significant differences $(P<0.05)$ of the associations between prognostic value and disease-free and overall survival rates in patients with early-stage cervical adenocarcinoma.

Abbreviations: FIGO, International Federation of Gynecology and Obstetrics; HR, hazard ratio; $95 \% \mathrm{Cl}$, $95 \%$ confidence interval.

findings in our study showed preoperative elevated serum CEA and CA125 were both significantly associated with stromal invasion in early stage ADC, and CA125 was associated with LNM. As we mentioned above, the prognosis significance of stromal invasion and LNM in ADC patients have been demonstrated. Survival analysis showed that preoperative elevated serum CEA and CA125 were significantly associated with shorter DFS and OS that indicative of poor prognosis. The ROC-AUC values showed moderate predictive value of CEA in 

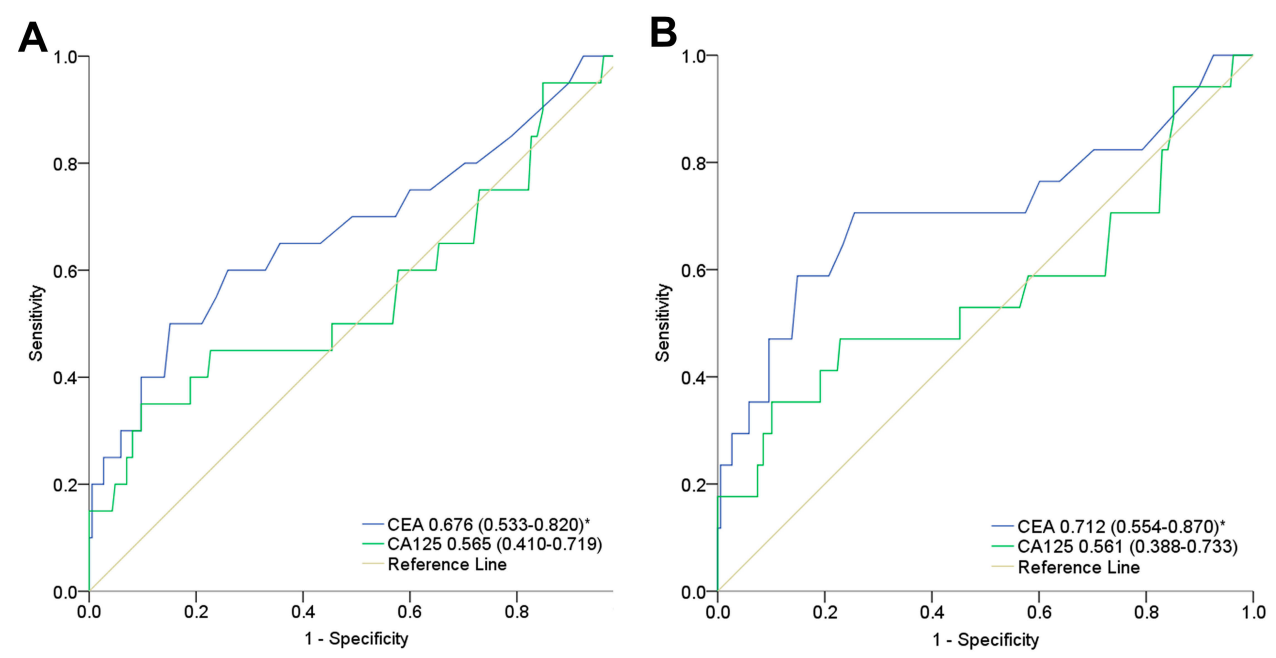

Figure 2 The receiver operating characteristic (ROC) curves for the preoperative serum CAI25 and CEA to predict disease-free survival (A) and overall survival (B). *Significant differences $(P<0.05)$ of the area under the curve $(A U C)$ of preoperative serum CEA to predict disease-free survival and overall survival.

predicting OS, while other serum tumor (including SCCAg, AFP, CA153, CA199, CA125) markers have no predictive value. The study indicated that preoperative serum CEA might be associated with early stage ADC prognosis. The sensitivity and specificity are maximized when preoperative serum CEA was $2.05 \mathrm{ng} / \mathrm{mL}$, which is below the upper limit $(5.0 \mathrm{ng} / \mathrm{mL})$ of the normal range.

In this study, DFS and OS of early stage ADC were up to $50 \%$ when serum CEA and CA125 was elevated simultaneously. Many studies focused on the use of multiple tumor markers to increase prognostic accuracy. ${ }^{14,22,36} \mathrm{In}$ the search for predictors of breast cancer, Li combined preoperative serum CEA and CA125 and concluded that it could be used as an independent predictor of breast cancer prognosis. ${ }^{22}$ In an analogous fashion, we combined preoperative serum measurements of CEA and CA125 and found that simultaneously elevated CA125 and CEA were significantly associated with FIGO stage, BMI and LNM. Moreover, survival analysis demonstrated that the elevated combination of CEA and CA125 was significantly associated with shorter DFS and OS. Multivariate analysis further verified that the combination of preoperative CEA and CA125 was an independent predictor of shorter DFS and OS of earlystage ADC patients. Thus, our results suggest that the combination of preoperative CEA and CA125 could be a key preoperative tumor marker of poor prognosis of early-stage ADC patients.

Michela and Ren each identified elevated pretreatment levels of SCC-Ag as a prognostic factor in early-stage CC. ${ }^{10,18}$ Serum AFP, CA153 and CA199 are classical tumor markers with abnormal expression in various human malignancies, ${ }^{17,19}$ but we did not find the association of these tumor markers with disease prognosis in early-stage ADC.

It's worth thinking about human papilloma virus (HPV) has been shown to be a key factor in the initiation and development of CC. The association between HPV and ADC has also been further studied. Chen found that HPV 18 accounted for a larger proportion in ADC. ${ }^{37}$ Mabuchi found that HPV 18 can be used as a prognostic factor to evaluate the prognosis of ADC. ${ }^{38}$ However, in our study, we mainly focused on the predictive effect of preoperative serum tumor markers on early ADC prognosis. In the future research, we will focus on this problem.

Table 4 Sensitivity, Specificity and Youden Index Using Cut-off Points for the Preoperative Serum CAI 25 and CEA to Predict DiseaseFree Survival and Overall Survival

\begin{tabular}{|l|l|l|l|l|l|l|l|l|}
\hline \multirow{4}{*}{} & \multicolumn{4}{|l|}{ Disease-Free Survival } & \multicolumn{2}{l|}{ Overall Survival } \\
\cline { 2 - 9 } & Cut-off & Sens (\%) & Spec (\%) & Youden Index & Cut-off & Sens (\%) & Spec (\%) & Youden Index \\
\hline CAI25 & 32.6 & 35 & 90.27 & 0.25 & 32.6 & 35.29 & 89.89 & 0.25 \\
CEA & 2.85 & 50 & 84.86 & 0.35 & 2.05 & 70.59 & 74.47 & 0.45 \\
\hline
\end{tabular}

Abbreviations: Sens, sensitivity; Spec, specificity. 
The major limitation of our study is that it is a singlecenter retrospective study. Additionally, the number of patients with elevated preoperative serum tumor markers was small, especially the group with the elevated combination of CA125 and CEA. Hence, the results may be biased. In the future, large-scale prospective clinical studies are necessary to ascertain whether the combined examination of preoperative serum CEA and CA125 could be an independent prognostic biomarker and lead to improvement of patient survival in early-stage ADC.

\section{Conclusion}

We have demonstrated that elevated preoperative serum CA125 and CEA alone is related to multiple clinicopathological features and has prognostic value in early-stage ADC patients. Moreover, our present study has confirmed the independent prognostic value of the combined evaluation of preoperative serum CEA and CA125 levels for early-stage ADC patients. Preoperative serum CA125 and CEA levels can provide additional prognostic information and may be useful in treatment option. Therefore, the tumor markers are a promising avenue for risk evaluation and determination of adjuvant treatment strategies in clinical practice, although our findings should be further validated. Further clinical trials are needed to clarify the utility of these serum biomarkers in decision-making management and treatment for ADC.

\section{Acknowledgments}

We thank International Science Editing (http://www.inter nationalscienceediting.com) for editing this manuscript.

\section{Funding}

This study was supported by Zhejiang Provincial Natural Science Foundation of China (Grant No. LY18H160004). The funder had no role in the study design, data collection and analysis, decision to publish, or preparation of the paper.

\section{Disclosure}

The authors report no conflicts of interest in this work.

\section{References}

1. van der Horst J, Siebers AG, Bulten J, et al. Increasing incidence of invasive and in situ cervical adenocarcinoma in the Netherlands during 2004-2013. Cancer Med. 2017;6(2):416-423. doi:10.1002/cam4.971

2. Williams NL, Werner TL, Jarboe EA, et al. Adenocarcinoma of the cervix: should we treat it differently? Curr Oncol Rep. 2015;17(4):17. doi:10.1007/s11912-015-0440-6
3. Park KJ. Cervical adenocarcinoma: integration of HPV status, pattern of invasion, morphology and molecular markers into classification. Histopathology. 2020;76(1):112-127. doi:10.1111/his.13995

4. Wang J, Elfström KM, Andrae B, et al. Cervical cancer case-control audit: results from routine evaluation of a nationwide cervical screening program. Int $J$ Cancer. 2020;146(5):1230-1240. doi:10.1002/ ijc. 32416

5. Smith HO, Tiffany MF, Qualls CR, et al. The rising incidence of adenocarcinoma relative to squamous cell carcinoma of the uterine cervix in the United States-a 24-year population-based study. Gynecol Oncol. 2000;78(2):97-105. doi:10.1006/gyno.2000.5826

6. Aime M, Jim C, Katrina S, et al. Risk of persistent and recurrent cervical neoplasia following incidentally detected adenocarcinoma in situ. Am J Obstet Gynecol. 2017;216(3):272-e1.

7. Gien LT, Beauchemin MC, Thomas G. Adenocarcinoma: a unique cervical cancer. Gynecol Oncol. 2010;116(1):140-146. doi:10.1016/j. ygyno.2009.09.040

8. Gadducci A, Guerrieri ME, Cosio S. Adenocarcinoma of the uterine cervix: pathologic features, treatment options, clinical outcome and prognostic variables. Crit Rev Oncol Hematol. 2019;135:103-114. doi:10.1016/j.critrevonc.2019.01.006

9. Tsai CC, Liu YS, Huang EY, et al. Value of preoperative serum CA125 in early-stage adenocarcinoma of the uterine cervix without pelvic lymph node metastasis. Gynecol Oncol. 2006;100(3):591-595. doi:10.1016/j.ygyno.2005.09.049

10. Michela S, Achilarre MT, Sandri B, et al. Squamous cell carcinoma antigen (SCC-Ag) during follow-up of cervical cancer patients: role in the early diagnosis of recurrence. Gynecol Oncol. 2016;142 (1):115-119. doi:10.1016/j.ygyno.2016.04.029

11. Zhao L, Zheng Y, Ji Y, et al. The expression of special AT-rich binding protein 1 in cervical cancer and its clinical significance. Onco Targets Ther. 2019;12:945-951. doi:10.2147/OTT.S191414

12. Halle MK, Ojesina AI, Engerud H, et al. Clinicopathologic and molecular markers in cervical carcinoma: a prospective cohort study. Am J Obstet Gynecol. 2017;217(4):432.e1-432.e17. doi:10. 1016/j.ajog.2017.05.068

13. Shao Y, Sun X, He Y, et al. Elevated levels of serum tumor markers CEA and CA15-3 are prognostic parameters for different molecular subtypes of breast cancer. PLoS One. 2015;10(7):e0133830. doi:10.1371/journal.pone. 0133830

14. Xu F, Li Y, Fan L, et al. Preoperative SCC-Ag and thrombocytosis as predictive markers for pelvic lymphatic metastasis of squamous cervical cancer in early FIGO stage. $J$ Cancer. 2018;9(9):1660-1666. doi: $10.7150 /$ jca. 24049

15. Bender DP, Sorosky JI, Buller RE, et al. Serum CA 125 is an independent prognostic factor in cervical adenocarcinoma. Am J Obstet Gynecol. 2003;189(1):113-117. doi:10.1067/mob.2003.443

16. Kubota H, Tsujino K, Sulaiman NS, et al. Comparison of salvage therapies for isolated para-aortic lymph node recurrence in patients with uterine cervical cancer after definitive treatment. Radiat Oncol. 2019;14(1):236. doi:10.1186/s13014-019-1442-6

17. Wang X-F, Wu Y-H, Wang M-S, et al. CEA, AFP, CA125, CA153 and CA199 in malignant pleural effusions predict the cause. Asian Pac J Cancer Prev. 2014;15(1):363-368. doi:10.7314/APJCP.2014.15.1.363

18. Ren J, Zhou ZL, Xu S, et al. Prognostic significance of cytokeratin 19 and squamous cell cancer antigen in histologically negative sentinel lymph nodes of cervical squamous cell carcinoma. Int $J$ Gynecol Cancer. 2016;26(9):1679-1685. doi:10.1097/IGC.0000000000000 813

19. Wang HP, Wu HY, Wang Y, et al. Combined detection of tumor markers and serum inflammatory factors in the diagnosis and treatment of gynecologic oncology. J Biol Regul Homeost Agents. 2017;31(3):691-695.

20. Feng F, Tian Y, Xu G, et al. Diagnostic and prognostic value of CEA, CA19-9, AFP and CA125 for early gastric cancer. BMC Cancer. 2017;17(1):737. doi:10.1186/s12885-017-3738-y 
21. Chen Y, Gao SG, Chen JM, et al. Serum CA242, CA199, CA125, CEA, and TSGF are biomarkers for the efficacy and prognosis of cryoablation in pancreatic cancer patients. Cell Biochem Biophys. 2015;71(3):1287-1291. doi:10.1007/s12013-014-0345-2

22. Li X, Dai D, Chen B, et al. Prognostic values of preoperative serum CEA and CA125 levels and nomograms for young breast cancer patients. Onco Targets Ther. 2019;12:8789-8800. doi:10.2147/OTT.S221335

23. Zhou J, Wu SG, Sun JY, et al. Comparison of clinical outcomes of squamous cell carcinoma, adenocarcinoma, and adenosquamous carcinoma of the uterine cervix after definitive radiotherapy: a population-based analysis. J Cancer Res Clin Oncol. 2017;143 (1):115-122. doi:10.1007/s00432-016-2246-9

24. Ramirez PT, Frumovitz M, Pareja R, et al. Minimally invasive versus abdominal radical hysterectomy for cervical cancer. $N$ Engl J Med. 2018;379(20):1895-1904. doi:10.1056/NEJMoa1806395

25. Lee J-Y, Kim YT, Kim S, et al. Prognosis of cervical cancer in the era of concurrent chemoradiation from National Database in Korea: a comparison between squamous cell carcinoma and adenocarcinoma. PLoS One. 2015;10(12):e0144887. doi:10.1371/journal.pone.0144887

26. Glorimar R-C, Chen H, Niu S, et al. Cervical adenocarcinoma: histopathologic features from biopsies to predict tumor behavior. Am J Surg Pathol. 2020;44(2):247-254. doi:10.1097/PAS.0000000000001379

27. Zong L, Zhang Q, Kong Y, et al. The tumor-stroma ratio is an independent predictor of survival in patients with 2018 FIGO stage IIIC squamous cell carcinoma of the cervix following primary radical surgery. Gynecol Oncol. 2020;156(3):676-681. doi:10.1016/j.ygyno.2019.12.022

28. Uppal S, Gehrig PA, Peng K, et al. Recurrence rates in patients with cervical cancer treated with abdominal versus minimally invasive radical hysterectomy: a multi-institutional retrospective review study. J Clin Oncol. 2020;38(10):1030-1040. doi:10.1200/JCO.19.03012

29. Sauerbrei W, Taube SE, McShane LM, et al. Reporting recommendations for tumor marker prognostic studies (REMARK): an abridged explanation and elaboration. $J$ Natl Cancer Inst. 2018;110 (8):803-811. doi:10.1093/jnci/djy088
30. Isabelle M, Perrine GG, Paul B, et al. Serum CA125 and ascites leptin level ratio predicts baseline clinical resistance to first-line platinum-based treatment and poor prognosis in patients with high grade serous ovarian cancer. Am J Cancer Res. 2019;9(1):160-170.

31. You W, Sheng N, Yan L, et al. The difference in prognosis of stage II and III colorectal cancer based on preoperative serum tumor markers. J Cancer. 2019;10(16):3757-3766. doi:10.7150/jca.31660

32. Guo Q, Zhu J, Wu Y, et al. Predictive value of preoperative serum squamous cell carcinoma antigen (SCC-Ag) level on tumor recurrence in cervical squamous cell carcinoma patients treated with radical surgery: a single-institution study. Eur J Surg Oncol. 2020;46(1):131-138. doi:10.1016/j.ejso.2019.08.021

33. Lin W, Cao D, Shen K. Prognostic significance of preoperative serum CEA in primary mucinous ovarian carcinoma: a retrospective cohort study. Cancer Manag Res. 2018;10:6913-6920. doi:10.2147/ CMAR.S186258

34. Ramona CD-P, Mignon K-P, Thomas H, et al. Clinical performance of LOCITM-based tumor marker assays for tumor markers CA 15-3, CA 125, CEA, CA 19-9 and AFP in gynecological cancers. Tumour Biol. 2017;39(10):1010428317730246.

35. Li X, Xu Y, Zhang L. Serum CA153 as biomarker for cancer and noncancer diseases. Prog Mol Biol Transl Sci. 2019;162:265-276.

36. Kazarian A, Blyuss O, Metodieva G, et al. Testing breast cancer serum biomarkers for early detection and prognosis in pre-diagnosis samples. Br J Cancer. 2017;116(4):501-508. doi:10.1038/bjc.2016.433

37. Chen W, Sun H, Molijn A, et al. The variable characteristics of human papillomavirus in squamous cell carcinoma and adenocarcinoma of cervix in China. $J$ Low Genit Tract Dis. 2018;22 (4):355-361. doi:10.1097/LGT.0000000000000408

38. Mabuchi Y, Yahata T, Kobayashi A, et al. Clinicopathologic factors of cervical adenocarcinoma stages IB to IIB. Int J Gynecol Cancer. 2015;25(9):1677-1682. doi:10.1097/IGC.0000000000000542

\section{Publish your work in this journal}

OncoTargets and Therapy is an international, peer-reviewed, open access journal focusing on the pathological basis of all cancers, potential targets for therapy and treatment protocols employed to improve the management of cancer patients. The journal also focuses on the impact of management programs and new therapeutic agents and protocols on patient perspectives such as quality of life, adherence and satisfaction. The manuscript management system is completely online and includes a very quick and fair peer-review system, which is all easy to use. Visit http://www.dovepress.com/ testimonials.php to read real quotes from published authors. 